\title{
Solvent-water extraction method for the evaluation of polycyclic aromatic hydrocarbons bioavailability in coal-tar-contaminated soils
}

\author{
P. H. Lee $\cdot$ K. P. Chao $\cdot$ S. K. Ong
}

Received: 23 August 2012/Revised: 9 May 2013/Accepted: 21 October 2013/Published online: 7 November 2013

(C) Islamic Azad University (IAU) 2013

\begin{abstract}
A solvent-water extraction method was proposed as an assessment tool to estimate the bioavailability of polycyclic aromatic hydrocarbons in coal-tar-contaminated soils. The approach taken was to measure the percent of polycyclic aromatic hydrocarbons extracted by a solvent-water mixture and comparing the results with the percent of polycyclic aromatic hydrocarbons degraded in a soil slurry reactor. Five soil samples from three former manufactured gas plant sites and a coal-tar disposal site which were operated between 1880 and 1947, and 1945 and 1950, respectively, in Iowa, USA were used in this study. Extraction experiments were conducted using acetone-water or ethanol-water mixtures with solvent volume fractions ranging from 1.0 to $0.4(\mathrm{v} / \mathrm{v})$. The percent of polycyclic aromatic hydrocarbons extracted from the various soils decreased as the volume fraction of the solvent in the solvent-water mixture was reduced. An acetone-water mixture of 0.6 was found to be appropriate in correlating the percent of polycyclic aromatic hydrocarbons degraded to the percent of polycyclic aromatic hydrocarbons extracted. For the first correlation, the percent extracted and the percent biodegraded were modified by using the molecular weights and $\log K_{\mathrm{ow}}$ of polycyclic aromatic hydrocarbons, respectively. For the second correlation, the
\end{abstract}

Electronic supplementary material The online version of this article (doi:10.1007/s13762-013-0405-y) contains supplementary material, which is available to authorized users.

\section{P. H. Lee $\cdot$ S. K. Ong}

Department of Civil, Construction and Environmental

Engineering, Iowa State University, Ames, IA 50011, USA

K. P. Chao $(\bowtie)$

Department of Occupational Safety and Health, China Medical

University, 91 Hsueh-Shih Rd., Taichung 40402, Taiwan

e-mail: kpchao@mail.cmu.edu.tw equation relating the percent extracted and the percent biodegraded was modified using soil properties such as organic carbon content and percent of clay and silt. Although the experiments were conducted for a limited number of soils, the extraction method appeared to be a good starting point in estimating the bioavailability of polycyclic aromatic hydrocarbons in coal-tar-contaminated soils.

Keywords Acetone - Aromatic hydrocarbons . Bioavailability $\cdot$ Solvent

\section{Introduction}

From the mid-1800s to the early 1950 s, manufactured gas or town gas produced by manufactured gas plants (MGPs) was the most common energy source in the USA and Europe for household heating, cooking, and lighting. One of the primary waste byproducts from the production of manufactured gas was coal-tar. Due to the lack of environmental regulatory oversight at that time, disposal of coal-tar near the manufacturing facilities and in landfills has contaminated valuable land and aquifers. With more than 5,000 former MGP sites in USA requiring some form of remediation (Hatheway 2011), several treatment or remediation technologies have been developed in the last decade to address this problem. These technologies include solvent extraction, chemical oxidation, steam flushing, supercritical extraction, phytoremediation, and bioremediation (Gan et al. 2009). Of the different remediation technologies available, bioremediation is probably the most cost-effective technology but needs a substantially long time to treat the soils to an acceptable concentration (Haritash and Kaushik 2009; Ward et al. 2003; Zhang et al. 2012). 
The primary constituents in coal-tar wastes from former MGP sites are polycyclic aromatic hydrocarbons (PAHs). High molecular weight (HMW) PAHs are defined as compounds containing four or more fused benzene rings. In general, HMW PAHs have very low aqueous solubilities, low vapor pressures, and high partition coefficients as compared to low molecular weight (LMW) PAHs (Olajire Abbas and Brack 2005). Information on the biodegradation of PAHs is well documented in the literature (Haritash and Kaushik 2009; Loick et al. 2009). LMW PAHs containing two or three fused benzene rings are readily degraded under aerobic conditions in the presence of appropriate organisms (Silva et al. 2009) while HMW PAHs degrade slowly and, in some situations, may be completely recalcitrant (Juhasz and Naidu 2000). Several researchers have indicated that PAHs are metabolized to ring fission products via dioxygenase-, monooxygenase-, or peroxidasecatalyzed reactions (Dean-Ross et al. 2002; Yousefi Kebria et al. 2009). A summary of the enzymatic mechanisms used by microorganisms to metabolize and detoxify PAHs along with their degradation pathways may be found in the study by Johnsen et al. (2005) and Sutherland et al. (1995).

A pressing issue with regard to the bioremediation of PAHs in soils is their availability for biodegradation. PAHs may be adsorbed and be bound to humic material in the soils, making them unavailable for microbial degradation (Wen et al. 2007). In addition, PAHs may reside in the micropores or nanopores of the soil particles that are smaller than $100 \mathrm{~nm}$, making them unavailable to the smallest bacterium (Nam and Alexander 1998). Several researchers have speculated that bioremediation of PAHs in soils may be visualized as a sequential process in which sorbed PAHs must desorb first into the aqueous phase before the PAHs become available to the microorganisms. Some researches have shown that the overall biodegradation rate of PAHs is controlled by desorption and diffusion of the PAHs through the intraparticles and not on the activity of the degrading microorganisms in the aqueous phase (Cornelissen et al. 1998). However, desorption of PAHs in soils cannot fully explain the lack of bioavailability of PAHs. For example, Zhang (1995) indicated that the in situ degradation rates of PAHs at a former MGP site were several times slower than the estimated degradation rates using mass transfer or desorption principles.

Information on the extent of PAHs "bioavailability" or the extent at which the PAHs will degrade within a time period is limited. Development of a simple tool that predicts rapidly the extent of PAHs degradation potential for a given soil or the concentration limit at which the soil may be cleaned within a reasonable time period will be highly useful (Kelsey et al. 1997; Loehr and Webster 1997). Extraction techniques may be used to predict the extent of PAHs bioavailability for coal-tar-contaminated soils.
Cornelissen et al. (1998) showed that the initial rapidly desorbing fraction of PAHs using a Tenax solid-phase extraction method could be used to roughly predict the extent of possible PAHs degradation in PAH-contaminated sediments and soils.

Nakles and Harju (1998) reported that mild solvent extraction might predict the availability of PAHs to earthworms and plants. They used $n$-butanol, $n$-propanol, methanol, and ethyl acetate as extraction solvents to correlate the uptake of anthracene, pyrene, and fluoranthene by earthworms, barley, and wheat plants. Correlation coefficients as high as 0.86 were obtained for the various combinations of solvents used and the test organisms. Similarly, Kelsey et al. (1997) found that mild extraction with $n$-butanol predicted phenanthrene mineralization in PAH-contaminated soils. Cuypers et al. (1998) found that solvent extraction [1:1 (v/v) acetone-water mixture] of PAH-contaminated sediment fractions gave a qualitative indication of the availability of PAHs in the PAH-contaminated sediments, but they did not compare their extraction results with PAHs biodegradation studies. However, Bergknut et al. (2007) investigated the bioavailability of PAHs in soils to earthworms and found that various chemical extraction techniques such as solid-phase microextraction, solvent mixtures, and surfactants were unable to estimate the bioavailability of PAHs.

The objective of this study was to assess the feasibility of using miscible solvent to estimate the PAHs fraction in the coal-tar-contaminated soils that may be biologically available. Solvent-water mixtures of two water miscible solvents, acetone and ethanol, were used for the extraction of 16 US EPA priority PAHs from five coal-tar-contaminated soils. To determine the extent of PAHs biodegradation in the coal-tar-contaminated soils, soil slurry bioreactors were used. The percent of PAHs extracted by the solvent-water mixtures were then correlated with the percent of PAHs biodegraded in the soil slurry bioreactors. The experiments of this study were conducted in the Department of Civil, Construction, and Environmental Engineering of Iowa State University in the mid-2000s.

\section{Materials and methods}

Soil sampling and characteristics

Five soil samples collected from four different coal-tarcontaminated sites in Iowa, USA, were used for the experiments. Soil sample S1 was taken from a coal-tar disposal pit that operated between 1945 and 1950 while sample S2 was obtained from a land-farming remediation unit built next to the disposal site in 1998. Sample S2 was a mixture of heavily contaminated soils from the disposal pit 
Table 1 Physical-chemical properties and initial PAHs concentrations for coal-tar-contaminated soils

\begin{tabular}{|c|c|c|c|c|c|}
\hline Properties & $\mathrm{S} 1$ & $\mathrm{~S} 2$ & $\mathrm{~S} 3$ & $\mathrm{~S} 4$ & S5 \\
\hline Soil texture ${ }^{a}$ & Sandy loam & Sandy clay loam & Sandy loam & Loam soil & Sandy loam \\
\hline Sand $(\%)$ & 60 & 54 & 64 & 41 & 64 \\
\hline Silt $(\%)$ & 26 & 24 & 18 & 35 & 25 \\
\hline Clay $(\%)$ & 14 & 22 & 18 & 24 & 11 \\
\hline Organic carbon $(\%)$ & 4.0 & 3.0 & 2.3 & 3.5 & 2.5 \\
\hline Soil moisture (\%) & 8.72 & 3.71 & 8.40 & 12.97 & 4.02 \\
\hline Soil pH & 7.65 & 7.09 & 6.52 & 7.22 & 7.81 \\
\hline \multicolumn{6}{|c|}{ Initial concentration of LMW PAHs $(\mathrm{mg} / \mathrm{kg})^{\mathrm{b}}$} \\
\hline Naphthalene & $35 \pm 3$ & $62 \pm 1$ & $986 \pm 54$ & $48 \pm 24$ & $379 \pm 12$ \\
\hline Acenaphthylene & $485 \pm 19$ & $61 \pm 1$ & $325 \pm 22$ & $190 \pm 5$ & $272 \pm 6$ \\
\hline Acenaphthene & $239 \pm 9$ & $34 \pm 0$ & $80 \pm 6$ & $37 \pm 1$ & $103 \pm 3$ \\
\hline Fluorene & $358 \pm 13$ & $62 \pm 1$ & $181 \pm 14$ & $139 \pm 3$ & $197 \pm 3$ \\
\hline Phenanthrene & $1,238 \pm 40$ & $128 \pm 4$ & $408 \pm 42$ & $347 \pm 11$ & $602 \pm 6$ \\
\hline Anthracene & $386 \pm 12$ & $54 \pm 1$ & $141 \pm 12$ & $113 \pm 3$ & $177 \pm 2$ \\
\hline Fluoranthene & $378 \pm 9$ & $98 \pm 3$ & $126 \pm 11$ & $128 \pm 2$ & $209 \pm 3$ \\
\hline Pyrene & $545 \pm 12$ & $146 \pm 5$ & $171 \pm 14$ & $173 \pm 3$ & $287 \pm 3$ \\
\hline \multicolumn{6}{|c|}{ Initial concentration of $H M W$ PAHs $(\mathrm{mg} / \mathrm{kg})^{\mathrm{b}}$} \\
\hline $\operatorname{Benzo}(a)$ anthracene & $188 \pm 3$ & $52 \pm 2$ & $66 \pm 4$ & $67 \pm 1$ & $92 \pm 1$ \\
\hline Chrysene & $202 \pm 3$ & $53 \pm 4$ & $66 \pm 4$ & $65 \pm 2$ & $92 \pm 1$ \\
\hline $\operatorname{Benzo}(b)$ fluoranthene & $82 \pm 2$ & $30 \pm 1$ & $25 \pm 1$ & $36 \pm 1$ & $53 \pm 1$ \\
\hline $\operatorname{Benzo}(k)$ fluoranthene & $84 \pm 1$ & $25 \pm 1$ & $30 \pm 2$ & $36 \pm 0$ & $54 \pm 1$ \\
\hline $\operatorname{Benzo}(a)$ pyrene & $143 \pm 3$ & $36 \pm 1$ & $48 \pm 3$ & $60 \pm 1$ & $90 \pm 2$ \\
\hline Indeno(1,2,3-cd)pyrene & $54 \pm 2$ & $18 \pm 1$ & $18 \pm 1$ & $28 \pm 1$ & $51 \pm 4$ \\
\hline $\operatorname{Dibenzo}(a, h)$ anthracene & $18 \pm 1$ & $7 \pm 0$ & $7 \pm 0$ & $9 \pm 0$ & $15 \pm 1$ \\
\hline $\operatorname{Benzo}(g, h, i)$ perylene & $57 \pm 2$ & $18 \pm 1$ & $17 \pm 1$ & $24 \pm 1$ & $51 \pm 3$ \\
\hline Total PAHs (mg/kg) & $4,494 \pm 129$ & $884 \pm 28$ & $2,694 \pm 188$ & $1,500 \pm 34$ & $2,724 \pm 10$ \\
\hline LMW PAHs $(\mathrm{mg} / \mathrm{kg})^{\mathrm{c}}$ & $3,664 \pm 112$ & $645 \pm 16$ & $2,417 \pm 172$ & $1,174 \pm 32$ & $2,227 \pm 15$ \\
\hline HMW PAHs $(\mathrm{mg} / \mathrm{kg})^{\mathrm{d}}$ & $830 \pm 18$ & $239 \pm 11$ & $276 \pm 17$ & $326 \pm 6$ & $498 \pm 14$ \\
\hline
\end{tabular}

${ }^{\text {a }}$ Based on USDA modified soil texture classification

${ }^{b}$ PAH concentration (on dry weight basis): mean \pm standard deviation $(\mathrm{mg} / \mathrm{kg}$ )

${ }^{c}$ LMW PAHs: LPAH1, naphthalene; LPAH2, acenaphthylene; LPAH3, acenaphthene; LPAH4, fluorene; LPAH5, phenanthrene; LPAH6, anthracene; LPAH7, fluoranthene; LPAH8, pyrene

${ }^{\mathrm{d}}$ HMW PAHs: HPAH1, benzo( $a$ )anthracene; HPAH2, chrysene, HPAH3, benzo $(b)$ fluoranthene; HPAH4, benzo $(k)$ fluoranthene; HPAH5, benzo(a)pyrene; HPAH6, indeno(1,2,3-cd)pyrene; HPAH7, dibenzo( $a, h)$ anthracene; HPAH8, benzo $(g, h, i)$ perylene

and lightly contaminated surface soils at the site. Soil samples S3, S4, and S5 were collected from three former MGP sites operated between 1915 and 1937, 1915-1947, and 1880-1947, respectively.

The five soils were collected using soil sampling spoons, placed in airtight aluminum containers and kept in a refrigerator at $4{ }^{\circ} \mathrm{C}$ until use. Prior to the soil slurry and extraction studies, the soil sample was homogenized by sieving through a $2 \mathrm{~mm}$ opening mesh. PAHs concentrations of the soil samples were measured using an acetone extraction method and gas chromatography (GC) with a flame ionization detector (FID) as described in Lee et al. (1999). All PAHs analyses were conducted in triplicates. In this method, $2 \mathrm{~g}$ of soil was placed with $5 \mathrm{~mL}$ of acetone in a $10 \mathrm{~mL}$ Teflon-lined screw cap glass tube. The contents in the tube were mixed for $24 \mathrm{~h}$ with a wrist action shaker (Model 75, Burrell Scientific, Pittsburgh, PA) at room temperature of $22 \pm 2{ }^{\circ} \mathrm{C}$ and were then centrifuged at 3,000 rpm for $40 \mathrm{~min}$. Five $\mu \mathrm{L}$ aliquot of the supernatant was extracted with a syringe and injected into and analyzed with a gas chromatograph (GC) (Model HP5890 A, Hewlett-Packard, Palo Alto, CA) equipped with a HP-5 capillary column and a flame ionization detector (FID). The initial oven temperature was $50{ }^{\circ} \mathrm{C}$ followed by a temperature ramp rate at $8{ }^{\circ} \mathrm{C} / \mathrm{min}$ to a final temperature of $302{ }^{\circ} \mathrm{C}$ for $5 \mathrm{~min}$. The injector temperature was set at $240{ }^{\circ} \mathrm{C}$, and the detector temperature was $320^{\circ} \mathrm{C}$. The dry mass of the soil was determined by decanting the 
supernatant and drying the soil in the tube in an oven at $105{ }^{\circ} \mathrm{C}$ for $24 \mathrm{~h}$. Each glass tube used was weighed before the soil, and acetone was added. PAHs concentrations in soil were reported on a dry weight basis. PAHs analytical standard solutions for calibration curves were purchased from Sigma-Aldrich (St. Louis, MO).

Soil texture was determined based on soil particle distribution test and USDA modified soil texture triangle (Boulding and Ginn 2004). Organic carbon contents in the soils were determined by the rapid dichromate oxidation method (Islam 2005). Table 1 shows the physical-chemical properties and initial PAHs concentrations of the five soil samples.

\section{Solvent extraction study}

The solvent-water mixtures used were either acetonewater or ethanol-water. The volume fraction $(v / v)$ of the solvents used in the solvent-water mixtures were $0.4,0.5$, $0.6,0.7,0.8$, and 0.9. For ethanol-water mixture experiments, an extraction was conducted with $100 \%$ ethanol. Deionized water was used for all dilutions. For the extraction experiments, two grams of soil sample were extracted with $5 \mathrm{~mL}$ of solvent-water mixture in a $10 \mathrm{~mL}$ glass tube with Teflon-lined screw cap. The analysis of PAHs in the supernatant of soil samples with the GC-FID was similar to that as described earlier.

\section{Soil slurry biodegradation studies}

Soil slurry biodegradation studies were conducted in a batch mode in a 1-L glass reactor under aerobic conditions. The constant contact of the soil with water coupled with the mixing in soil slurry reactors generally provided an environment that maximizes availability of PAHs. Therefore, the amount of PAHs remaining after reaching steady-state conditions would generally reflect the amount of PAHs that were not available. Approximately $150 \mathrm{~g}$ (dry weight basis) of contaminated soil was loaded into the reactor along with $750 \mathrm{~mL}$ of distilled water. Each reactor was seeded with $20 \mathrm{~mL}$ of supernatant from a 2-L mother reactor, which was aerated and fed every 3-4 weeks with about $300 \mathrm{~g}$ of PAHs-contaminated soils for several months to maintain a viable microbial community. No external microorganisms were added to the mother reactor, but instead the soil indigenous microorganisms were cultivated. In the operation of the mother reactor, the soil slurry bioreactors were supplemented with ammonium nitrate as a nitrogen source and $\mathrm{KH}_{2} \mathrm{PO}_{4}$ as a phosphate source. The amounts of nutrient added were based on a $\mathrm{C}: \mathrm{N}: \mathrm{P}$ ratio of 100:10:2 where the carbon fraction was assumed to be the total carbon content of the 16 PAHs present in the soil.
Each reactor was mixed with a mixer (Model PM6015, EMI Incorporated, Clinton, CT) and aerated using an air stone diffuser at an airflow rate of $200 \mathrm{~mL} / \mathrm{min}$. The dissolved oxygen concentration was maintained at above $3.0 \mathrm{mg} / \mathrm{L}$, and the $\mathrm{pH}$ of the slurry was kept between 6.5 and 8. Slurry samples were taken at various time periods, and the concentration of each PAHs in the soil was measured according to the method described by Pinelli et al. (1997) and Lee et al. (1999). A $10 \mathrm{~mL}$ slurry sample was placed in a $10-\mathrm{mL}$ glass tube and centrifuged at 3,000 rpm for $30 \mathrm{~min}$. The supernatant was discarded. Preliminary tests have shown that the supernatant contained negligible amount of PAHs. Five $\mathrm{mL}$ of pure acetone was then added to the soil residue, and the tube was shaken for $24 \mathrm{~h}$. The suspension was centrifuged at 3,000 rpm for $30 \mathrm{~min}$, and $5 \mathrm{~L}$ of the supernatant was analyzed by GC-FID using similar GC conditions as described earlier. The dry weight of soil was then determined by drying the soil sample at $105^{\circ} \mathrm{C}$ for $24 \mathrm{~h}$.

\section{Results and discussion}

\section{Solvent-water extraction experiments}

The percent of LMW and HMW PAHs extracted for the five soils with different acetone-water and ethanol-water mixtures are presented in Fig. 1a, b, respectively. The trends seen in Fig. 1 are reflective of the individual PAHs within its broad grouping of LMW and HMW PAHs. Lee et al. (1999) have shown that pure acetone is an effective solvent for the extraction and measurement of the PAHs present in the soil. As such, the PAHs extracted using both solvent and water mixtures in Fig. 1 are expressed as a percentage of the PAHs extracted using $100 \%$ acetone.

Except for sample S1, the percent of LMW and HMW PAHs extracted were all greater than $90 \%$ for acetonewater mixtures of 0.8 or more. A possible reason for the lower percent of LMW PAHs extracted for sample S1 may be the higher organic carbon content of S1, i.e., $4 \%$, in comparison with the other four soils. Nam and Alexander (1998) have found that soil properties have an impact on the amount extracted as PAHs may be tightly bound to the organic matter of the soil or located in the micropores and nanopores of clay and silts. As seen in Fig. 1, the percent extracted declined precipitously when an acetone-water mixture of 0.7 or less was used. About 6-26\% of the PAHs were extracted with an acetonewater mixture of 0.4 .

As expected, PAHs extracted by the ethanol-water mixtures were all less than that of the acetone-water mixtures for all five soils. In comparison with $100 \%$ acetone, the average percent of HMW PAHs extracted with pure ethanol were $73,79,79,79$, and $70 \%$ for samples $\mathrm{S} 1$, 

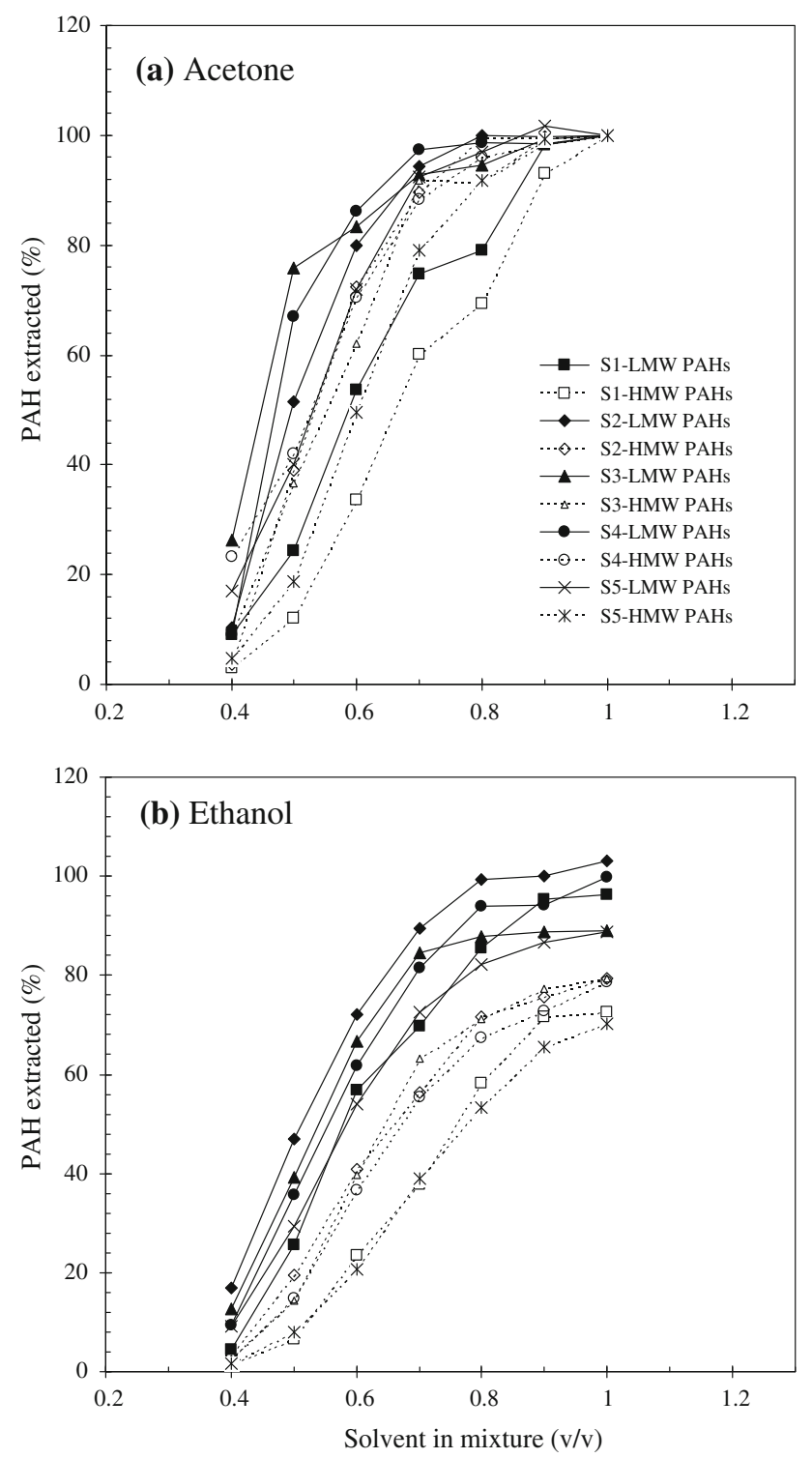

Fig. 1 Extraction of PAHs using different solvent-water mixtures for five different soils

S2, S3, S4, and S5, respectively. Pure ethanol extracted similar amounts of LMW PAHs as pure acetone except for sample S4 where a higher percentage of LMW PAHs were extracted. For an ethanol-water mixture of 0.7, the percent of HMW PAHs extracted were 38, 56, 63, 55, and $39 \%$ for sample S1, S2, S3, S4, and S5, respectively, while the percent of LMW PAHs extracted were 60, 90, 92, 88, and $79 \%$ for the same soils using an acetone-water mixture of 0.7. As in the acetone-water mixture experiments, the percents of LMW and HMW PAHs extracted from sample S1 by ethanol-water mixture were lower than that of the other four soils and a lower volume fraction of ethanol in the ethanol-water mixture resulted in a precipitous decline in the percent of PAHs extracted.
The above results showed that the pattern of decreasing extractability of PAHs with a lower solvent-water fraction may be used to estimate the extent of PAHs availability for biodegradation in soils. As seen in Fig. 1, the LMW PAHs were more easily extracted than the HMW PAHs for different solvent-water mixtures for the same soil. Similar results were obtained by Cuypers et al. (1998) with an acetone-water mixture of 0.5 where LMW PAHs were easily extracted but not for HMW PAHs such as 5-ring PAHs. Based on this observation, it is probable that the lower extraction potential of HMW PAHs as compared to LMW PAHs may be similar, to a certain extent, to the biodegradation potential of PAHs in the soil where LMW PAHs are more easily degraded than HMW PAHs (Froehner et al. 2012; Juhasz and Naidu 2000; Lu et al. 2012).

Extent of PAHs biodegradation in different soils

Figure 2 presents the biodegradation results of $16 \mathrm{PAHs}$ for sample S4 using the soil slurry reactor. Biodegradation of PAHs for the other four soil samples followed a similar degradation pattern (data not shown). After 35 days of operating the soil slurry bioreactor, the concentrations of PAHs in the five soils reached steady-state concentrations except for one or two PAHs such as benzo( $k)$ fluoranthene in sample S3. A large fraction of the 2- and 3-ring PAHs (naphthalene, acenaphthylene, acenaphthene, fluorene, phenanthrene, and anthracene) degraded within 14 days, while the 4-ring PAHs (fluoranthene, pyrene, benzo $(a)$ anthracene, and chrysene) only started to degrade after most of the 2- and 3-ring PAHs were removed. The 5and 6-ring PAHs that included benzo $(b)$ fluoranthene, benzo $(k)$ fluoranthene, benzo $(a)$ pyrene, indeno(1,2,3-

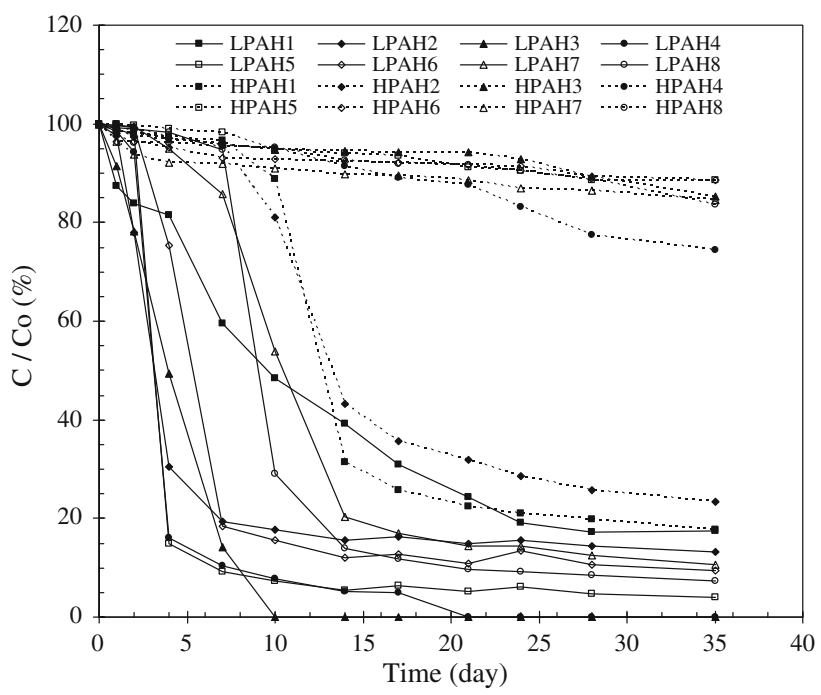

Fig. 2 Biodegradation of PAHs for sample S4 in soil slurry reactor 
cd)pyrene, dibenzo $(a, h)$ anthracene, and benzo $(g, h, i)$ perylene were degraded slowly with less than $20 \%$ degraded after 35 days. For all soil samples, a residual amount of PAHs remained after 35 days and these were generally 4-, 5- and 6-ring PAHs.

Some exceptions and trends for other soils not illustrated in Fig. 2 will be discussed (data not shown). Of the five soils tested, degradation of 2- and 3-ring PAHs was the fastest for sample S2, which may be related to its initial concentrations (Loehr and Webster 1997; Nnamchi et al. 2006). Naphthalene was completely removed from sample S3 within 4 days, but for samples S1 and S2, naphthalene continued to persist even up to 28 days. In the case of sample S4, low concentrations of naphthalene $(6 \mathrm{mg} / \mathrm{kg})$ remained even after 35 days. Besides naphthalene, other PAHs compounds that were completely removed were fluorene and acenaphthene. Benzo $(k)$ fluoranthene was the only 5- and 6-ring PAHs that was degraded significantly (about $50 \%$ ) in sample S2 within the 35-day study, while for all other soils, approximately $20 \%$ were degraded. The residual amounts of 2- and 4-ring PAHs remaining in the soil after 35 days clearly point toward the slowly desorbing or unavailable fraction present in the soil. For the 5- and 6-ring PAHs, the slow degradation observed may be due to their low solubility or being tightly bound to the soils and/ or the lack or absence of microbial activity essential for their degradation (Sutherland et al. 1995).

Figure 3 shows the degradation of the total PAHs for the five soil samples. There was a lag phase for both samples S1 and S4. Degradation of PAHs in sample S3 appeared to be the fastest of the five soils tested. For all soil samples, the total PAHs reached steady-state concentrations with a residual amount of PAHs (between 150 and $300 \mathrm{mg} / \mathrm{kg}$ ) remaining after 35 days. These PAHs were generally 4-, 5-,

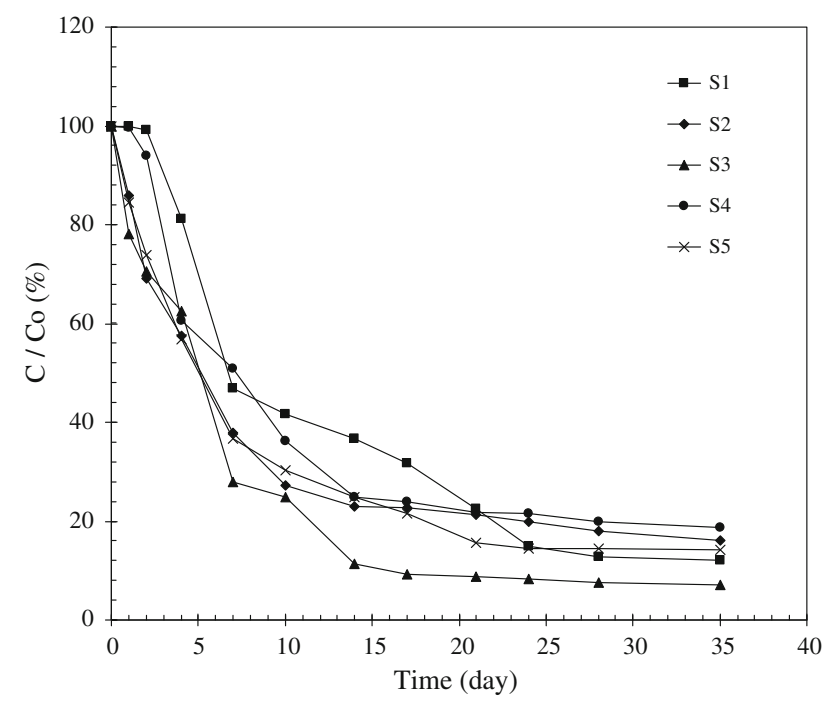

Fig. 3 Change in total PAHs for five samples in soil slurry reactors
Table 2 Percent (\%) degraded for 16 PAHs after 35 days for five samples in slurry reactors

\begin{tabular}{lrrrrr}
\hline Compound & \multicolumn{1}{c}{ S1 } & \multicolumn{1}{c}{ S2 } & \multicolumn{1}{c}{ S3 } & \multicolumn{1}{l}{ S4 } & \multicolumn{1}{l}{ S5 } \\
\hline LMW PAHs & & & & & \\
Naphthalene & 100.0 & 100.0 & 100.0 & 81.8 & 95.4 \\
Acenaphthylene & 90.9 & 75.1 & 93.2 & 86.1 & 90.9 \\
Acenaphthene & 100.0 & 100.0 & 100.0 & 100.0 & 100.0 \\
Fluorene & 100.0 & 100.0 & 100.0 & 100.0 & 95.9 \\
Phenanthrene & 98.7 & 95.2 & 100.0 & 95.7 & 96.5 \\
Anthracene & 95.2 & 87.1 & 95.4 & 90.2 & 91.5 \\
Fluoranthene & 93.7 & 91.0 & 100.0 & 88.8 & 84.8 \\
Pyrene & 94.0 & 92.5 & 97.1 & 92.4 & 85.3 \\
HMW PAHs & & & & & \\
Benzo $(a)$ anthracene & 90.7 & 84.0 & 89.0 & 81.6 & 79.3 \\
Chrysene & 81.3 & 86.0 & 86.3 & 75.6 & 76.0 \\
Benzo $(b)$ fluoranthene & 25.1 & 33.5 & 15.1 & 10.8 & 30.7 \\
Benzo $(k)$ fluoranthene & 31.8 & 60.0 & 33.3 & 22.1 & 35.7 \\
Benzo $(a)$ pyrene & 20.4 & 35.3 & 14.4 & 7.4 & 35.1 \\
Indeno(1,2,3-cd)pyrene & 23.6 & 28.9 & 13.3 & 7.3 & 32.4 \\
Dibenzo $(a, h)$ anthracene & 25.8 & 33.0 & 17.9 & 11.5 & 35.6 \\
Benzo $(g, h, i)$ perylene & 29.0 & 31.3 & 12.6 & 12.6 & 32.8 \\
\hline & & & & &
\end{tabular}

and 6-rings PAHs. To correlate the biodegradation of the PAHs for the five soils with the percent extracted using different solvent-water mixtures, the extent of PAHs degraded (expressed as a percent degraded) after 35 days was determined for the 16 PAHs and presented in Table 2.

Correlation between percent extracted and percent biodegraded

The percent of PAHs degraded reflect the amount of the individual PAHs in the soil that are available, which will be eventually degraded. For the five soils, there was a positive trend between the percent of PAHs degraded and the percent of PAHs extracted for different solvent-water mixture fractions as illustrated by the coefficients of determination $\left(R^{2}\right)$ in Table 3. The $R^{2}$ values provide an indirect measure of the strength of the correlation between the percent of PAHs biodegraded in the soil after 35 days and the percent of PAHs extracted. Table 3 shows that the $R^{2}$ values (0.74-0.88) for an acetone-water mixture of 0.6 for all soil samples were equal or higher than the other solvent-water mixtures. For an acetone-water fraction of 0.9 , the correlations were not strong $(<0.4)$ for all soils as acetone extracted the majority of the PAHs in the soil including HMW PAHs, which were only marginally biodegraded in the soil slurry bioreactors. Ethanol is a mild extractant with the best correlations (between 0.73 and 0.89 ) for an ethanol-water mixture fraction of 0.8 but was found to extract less PAHs than the acetone-water mixture. For ethanol- 
Table 3 Summary of $R^{2}$ values of linear regressions between percent biodegraded and percent extracted for five soils

\begin{tabular}{lccccc}
\hline Solvent fraction & $\mathrm{S} 1$ & $\mathrm{~S} 2$ & $\mathrm{~S} 3$ & $\mathrm{~S} 4$ & $\mathrm{~S} 5$ \\
\hline \multicolumn{2}{l}{ Ethanol-water mixture } & & & & \\
1.0 & 0.59 & 0.70 & 0.34 & 0.74 & 0.80 \\
0.9 & 0.72 & 0.77 & 0.63 & 0.84 & 0.87 \\
0.8 & 0.75 & 0.76 & 0.73 & 0.83 & 0.89 \\
0.7 & 0.74 & 0.71 & 0.75 & 0.74 & 0.86 \\
0.6 & 0.72 & 0.64 & 0.85 & 0.67 & 0.75 \\
0.5 & 0.35 & 0.54 & 0.70 & 0.63 & 0.60 \\
0.4 & 0.41 & 0.41 & 0.43 & 0.57 & 0.43 \\
Acetone-water mixture & & & & \\
0.9 & 0.17 & 0.01 & 0.22 & 0.20 & 0.40 \\
0.8 & 0.34 & 0.03 & 0.57 & 0.49 & 0.71 \\
0.7 & 0.59 & 0.39 & 0.70 & 0.65 & 0.80 \\
0.6 & 0.74 & 0.87 & 0.83 & 0.87 & 0.88 \\
0.5 & 0.61 & 0.58 & 0.74 & 0.69 & 0.69 \\
0.4 & 0.44 & 0.46 & 0.58 & 0.55 & 0.57 \\
\hline
\end{tabular}

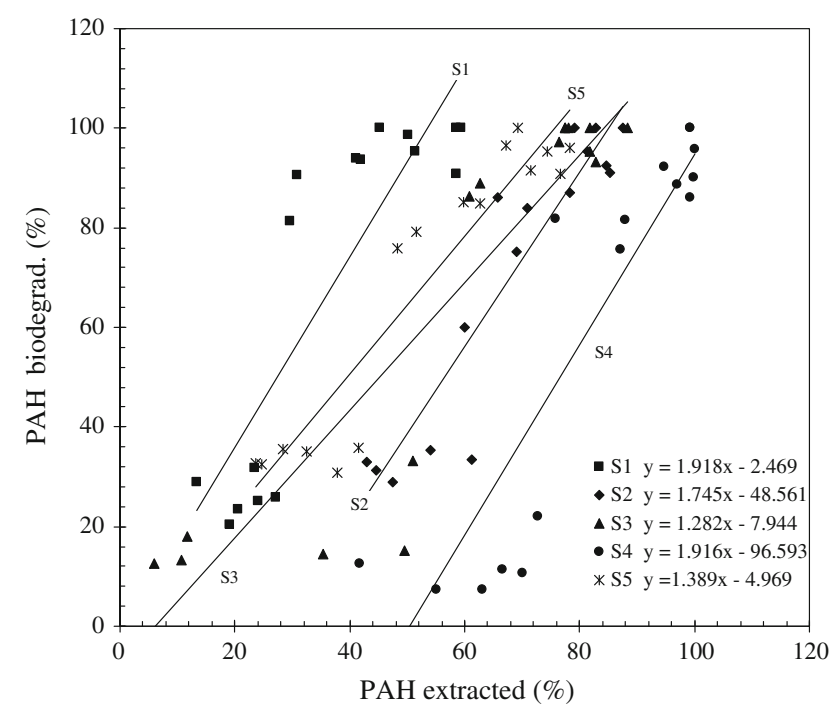

Fig. 4 Plot of PAHs extracted and biodegraded for five different soils using 0.6 volume fraction of acetone in acetone-water mixture

water fraction $<0.6$, the correlations for percent extracted to percent biodegraded were all $<0.7$. Based on the correlation results in Table 3, an acetone-water mixture of 0.6 may be appropriate to capture the necessary differences in individual PAHs extractability to delineate the extent of PAHs availability for the prediction of PAHs degradation in a PAHs-contaminated soil. This approach, however, seemed to be rather simplistic and must be further expanded since the extent of PAHs degradation for a given soil is also very much dependent on the PAHs properties, soil type and properties, and the aging process.

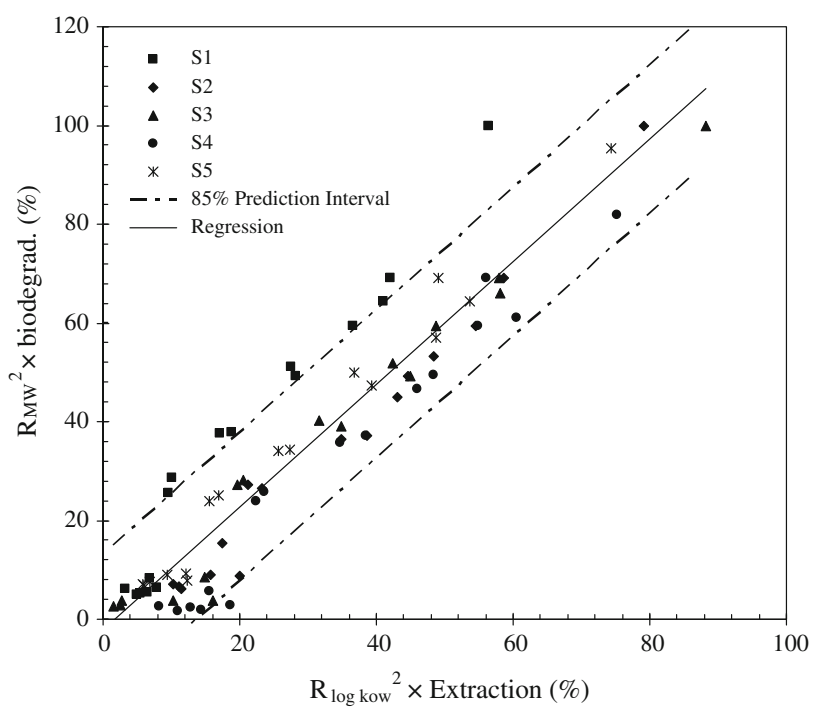

Fig. 5 Plot of percent PAHs extracted (modified with $R_{\log K_{\text {ow }}}$ ) and percent biodegraded (modified with $R_{\mathrm{MW}}$ ) for all five soils using acetone-water volume fraction of 0.6

Figure 4 presents a plot of the percent of PAHs extracted and the percent of PAHs degraded for all 16 PAHs using an acetone-water fraction of 0.6. If an ideal bioavailability test method is available, the percent biodegraded and the percent extracted would be plotted with a slope of one and an intercept of zero. This ideal line assumes that any available (or extracted) PAHs will be degraded and that the ideal test method measures the available PAHs. As seen in Fig. 4, the slopes of the correlations for each soil were larger than one. This result means that the acetone-water mixture of 0.6 extracted less of the more biodegradable PAHs (usually the LMW PAHs) but extracted more of the less biodegradable PAHs (usually the HMW PAHs). The negative values of intercepts showed that the percent degraded for HMW PAHs were much lower than the percent extracted. Therefore, adjustments must be made on the results of the extraction test to account for the properties of the soil samples and the PAHs, and the aging process.

The following two approaches were taken to provide a more generalized approach that includes the properties of the soils and the PAHs. In the first approach, the percent biodegraded and the percent extracted were modified by various dimensionless ratios. The ratios used were as follows:

$R_{\mathrm{MW}}=\frac{\mathrm{MW}_{\text {naphthalene }}}{\mathrm{MW}_{\mathrm{PAH}}}$

$R_{\log K_{\text {ow }}}=\frac{\log K_{\text {ow,naphthalene }}}{\log K_{\text {ow }, \text { PAH }}}$

where $\mathrm{MW}_{\text {naphthalene }}$ is the molecular weight of naphthalene; $\mathrm{MW}_{\mathrm{PAH}}$ is the molecular weight of the particular 
Table 4 Regression for slopes and intercepts versus soil fractions of four soil samples

\begin{tabular}{lll}
\hline Soil fraction & Regression & $R^{2}$ \\
\hline $\begin{array}{l}\text { Slope } \\
\text { Organic Carbon }\end{array}$ & Slope $=0.387 \times$ OC +0.476 & 0.866 \\
$\quad(\%)$ & \\
Clay $(\%)$ & Slope $=0.009 \times$ Clay +1.546 & 0.016 \\
Silt $(\%)$ & Slope $=0.036 \times$ Silt +0.802 & 0.683 \\
Sand $(\%)$ & Slope $=-0.019 \times$ Sand +2.761 & 0.404 \\
Clay + Silt $(\%)$ & Slope $=0.019 \times($ Clay + Silt $)+0.85$ & 0.404 \\
Intercept & & \\
Organic Carbon & Intercept $=-12.58 \times$ OC +2.962 & 0.041 \\
$\quad(\%)$ & & \\
Clay $(\%)$ & Intercept $=-9.159 \times$ Clay +141.3 & 0.806 \\
Silt $(\%)$ & Intercept $=-5.361 \times$ Silt +100.74 & 0.694 \\
Sand $(\%)$ & Intercept $=4.419 \times$ Sand -279.22 & 0.963 \\
Clay + Silt $(\%)$ & Intercept $=-$ & 0.963 \\
& $4.419 \times($ Clay + Silt $)+162.65$ & \\
\hline
\end{tabular}

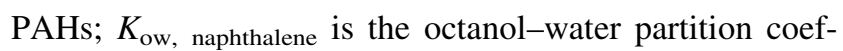
ficient of naphthalene; and $K_{\mathrm{ow}}$ PAHs is the octanol-water partition coefficient of the particular PAHs. Molecular weights and $\log K_{\mathrm{ow}}$ were used as they are generally related to the solubility of the PAHs in water, as well as the log $K_{\text {oc }}$, which reflects the extent of PAHs adsorption to soils (Schwarzenbach et al. 2002).

Attempts were made to modify the percent degraded and the percent extracted with the above ratios. Of all the attempts, the best correlation obtained was with the percent biodegraded modified by the square of $R_{\mathrm{MW}}$ and the percent extracted modified by the square of $R_{K_{\mathrm{ow}}}$. This is plotted as shown in Fig. 5. The correlation coefficient for this plot was 0.94 . Note that most of the soils fall within the slope of one and within the $85 \%$ prediction interval of the regression line.

In the second approach, the slopes and the intercepts of the regressions as shown in Fig. 4 were correlated with the various soil fractions. In this approach, only four soil samples were used while sample S5 was used as the test soil for the correlation since sample S5 was received about 4 months after the other four soils were tested. As indicated above, an ideal bioavailability test method would give a slope of one and an intercept of zero for a plot of percent biodegraded versus the percent extracted. Table 4 shows that the organic carbon contents of soil samples correlated well with the slopes $\left(R^{2}=0.866\right)$. Furthermore, as seen in Table 4 , the slopes of the linear regression increased with the organic carbon content of the soil samples. This means that for a given PAHs in a soil with high organic carbon content, less was extracted by the acetone-water mixture than what was actually degraded in a soil slurry reactor.
The relationship between the organic carbon content and the slope is given by:

Slope $=0.387 \times$ OC $(\%)+0.476$.

On the other hand, the intercepts were also regressed against the different soil fractions. The percent clay plus silt fractions were found to correlate well with the intercepts with $R^{2}$ of 0.963 as presented in Table 4 . Even though the $R^{2}$ for the correlation of percent sand and the intercepts was the same for the correlation of percent clay plus silt and the intercepts, the percent sand correlation was not selected as it is known that clay and silt have higher surface area that would control the mass of PAHs sorbed. The correlation shows that with more clay and silt present, the percent biodegraded for a given PAHs would be lower for a given percent extraction. The relationship between the clay plus silt fraction and the intercept is given by:

Intercept $=-4.419($ clay + silt $)(\%)+162.65$.

Using the above two relationships, the following equation relating the percent biodegraded and the percent extracted using acetone-water mixture of 0.6 was obtained:

$$
\begin{aligned}
\text { Biodegraded }(\%)= & {[0.387 \times \text { OC }(\%)+0.476] } \\
& \times \text { Extracted }(\%)-4.419(\text { clay } \\
& + \text { silt })(\%)+162.65 .
\end{aligned}
$$

Since the acetone-water extraction method is not an ideal bioavailability test method, the term containing the percent organic carbon modifies the slope of Eq. 3 to a value of approximately one. This may be viewed as the organic carbon in the soils impacting the extraction of LMW PAHs more than the degradation of LMW PAHs that were sorbed onto the organic carbon. The second term with the percent clay and silt modifies the intercept of Eq. 3 to a value of approximately zero. This can be viewed as HMW PAHs, which were associated with the clay and silt, were probably more easily extracted than biodegraded.

Equation 3 was tested against sample S5 to evaluate the appropriateness of the equation for the estimation of the percent of PAHs degraded. As presented in Table 5, the estimated percent of each PAHs degraded varied from about $1-24 \%$ of the actual measured percent biodegraded. The equation overestimated the percent biodegraded for LMW PAHs such as naphthalene, acenaphthylene, acenaphthene, anthracene, and fluorene. Although the overall estimation of percent PAHs biodegraded was higher than the experimental results in this case, most of the differences between the estimation and experiment were less than $13 \%$.

In comparison with other methods, Cuypers et al. (2002) used hydroxypropyl- $\beta$-cyclodextrin (HPCD) and Triton X-00 as extractants and found that HPCD extraction of 3and 4-rings PAHs from a harbor sediment with about $2,000 \mathrm{mg} / \mathrm{L}$ of PAHs was similar to that of a biodegradation test. However, the HPCD extraction method over 
Table 5 Estimated biodegradation of PAHs in sample S5 from acetone-water mixture extraction and soil properties

\begin{tabular}{|c|c|c|c|c|}
\hline Compounds & Extracted $^{\mathrm{a}}(\%)$ & Biodegraded (\%) & Estimated $^{\mathrm{b}}(\%)$ & Difference $^{\mathrm{c}}(\%)$ \\
\hline Naphthalene & 74 & 95 & 108 & +13 \\
\hline Acenaphthylene & 77 & 91 & 112 & +21 \\
\hline Acenaphthene & 69 & 100 & 101 & +1 \\
\hline Fluorene & 78 & 96 & 114 & +18 \\
\hline Phenanthrene & 67 & 97 & 98 & +1 \\
\hline Anthracene & 71 & 91 & 104 & +13 \\
\hline Fluoranthene & 63 & 85 & 91 & +6 \\
\hline Pyrene & 60 & 85 & 87 & +2 \\
\hline Benzo $(a)$ anthracene & 52 & 79 & 75 & -4 \\
\hline Chrysene & 48 & 76 & 71 & -5 \\
\hline $\operatorname{Benzo}(b)$ fluoranthene & 38 & 31 & 55 & +24 \\
\hline $\operatorname{Benzo}(k)$ fluoranthene & 41 & 36 & 60 & +24 \\
\hline Benzo $(a)$ pyrene & 33 & 35 & 47 & +12 \\
\hline Indeno(1,2,3-cd)pyrene & 25 & 32 & 36 & +4 \\
\hline Dibenzo $(a, h)$ anthracene & 28 & 36 & 41 & +5 \\
\hline $\operatorname{Benzo}(g, h, i)$ perylene & 24 & 33 & 35 & +2 \\
\hline
\end{tabular}

${ }^{\text {a }}$ PAH extracted by acetone-water mixture

b Estimated biodegradation of PAHs using Eq. 3

${ }^{c}$ Difference of biodegraded PAHs between measurement and estimation

predicted the biodegradation of 5-rings PAHs. The proposed mild solvent extraction method (using an acetonewater mixture fraction of 0.6) similarly over predicted the bioavailability of HMW PAHs.

The above experimental results showed that the mild solvent extraction method may be used as an assessment tool to estimate the extent of PAHs degradation in soils and therefore indirectly the PAHs bioavailability. Although the number of soils tested was small, this assessment tool is a first step toward developing a method that estimates the availability of PAHs in coal-tar-contaminated soils. This tool may be used to estimate the feasibility of a bioremediation technology in treating a given soil to regulatory clean-up levels. In addition, it is possible that this extraction method can be extended to sediments and other organic contaminants by finding the appropriate acetonewater mixture needed.

\section{Conclusion}

A solvent-water extraction method was proposed and tested as an assessment tool to estimate the percent of PAHs in soils that may be available for biodegradation. The percent of PAHs extracted using an acetone-water mixture of 0.6 for five different soils were found to correlate with the percent of PAHs degraded using soil slurry reactors. Two correlations relating the percent PAHs degraded, percent PAHs extracted using 0.6 acetone-water mixture, soil and PAHs properties were developed. For the first correlation, the percent extracted and the percent biodegraded were modified with the ratio of the PAHs molecular weights and the ratios of $\log K_{\text {ow }}$, respectively. The second correlation modifies the equation for the percent extracted and the percent biodegraded with soil properties such as organic carbon and percent of clay and silt. The correlation was found to predict well the biodegradation potential for the test soil with errors ranging from 1 to $24 \%$ depending on the PAHs. The mild solvent extraction method appeared to be a simple and quick assessment tool that can be used for the estimation of the extent of PAHs degradation and their bioavailability in coal-tar-contaminated soils.

Acknowledgments The study was supported by Iowa State University. The authors are grateful to the anonymous reviewers for their comments and suggestions that improved the clarity and content of the manuscript.

\section{References}

Bergknut M, Sehlin E, Lundstedt S, Andersson PL, Haglund P, Tysklind M (2007) Comparison of techniques for estimating PAH bioavailability: uptake in Eisenia fetida, passive samplers and leaching using solvents and additives. Environ Pollut 145(1):154-160

Boulding JR, Ginn JS (2004) Practical handbook of soil, vadose zone, and ground-water contamination: assessment, prevention, and remediation, 2nd edn. Lewis, London 
Cornelissen G, Rigterink H, Ferdinandy MMA, Van Noort PCM (1998) Rapidly desorbing fractions of PAHs in contaminated sediments as a predictor of the extent of bioremediation. Environ Sci Technol 32(7):966-970

Cuypers MP, Grotenhuis JTC, Rulkens WH (1998) Characterisation of PAH-contaminated sediments in a remediation respective. Water Sci Technol 37(6-7):157-164

Cuypers C, Pancras T, Grotenhuis T, Rulkens W (2002) The estimation of PAH bioavailability in contaminated sediments using hydroxypropyl- $\beta$-cyclodextrin and Triton X-100 extraction techniques. Chemosphere 46(8):1235-1245

Dean-Ross D, Moody J, Cerniglia CE (2002) Utilisation of mixtures of polycyclic aromatic hydrocarbons by bacteria isolated from contaminated sediment. FEMS Microbiol Ecol 41(1):1-7

Froehner S, Dombroski LF, Machado KS, Scapulatempo Fernandes C, Bessa M (2012) Estimation of bioavailability of polycyclic aromatic hydrocarbons in river sediments. Int $\mathrm{J}$ Environ Sci Technol 9(3):409-416

Gan S, Lau EV, Ng HK (2009) Remediation of soils contaminated with polycyclic aromatic hydrocarbons (PAHs). J Hazard Mater 172(2-3):532-549

Haritash AK, Kaushik CP (2009) Biodegradation aspects of polycyclic aromatic hydrocarbons (PAHs): a review. J Hazard Mater 169(1-3):1-15

Hatheway AW (2011) Remediation of former manufactured gas plants and other coal-tar sites. CRC Press, Boca Raton

Islam KR (2005) Organic carbon content assessment methods. In: Lal $\mathrm{R}$ (ed) Encyclopedia of soil science, 2nd edn. CRC Press, Boca Raton

Johnsen AR, Wick LY, Harms H (2005) Principles of microbial PAHdegradation in soil. Environ Pollut 133(1):71-84

Juhasz AL, Naidu R (2000) Bioremediation of high molecular weight polycyclic aromatic hydrocarbons: a review of the microbial degradation of benzo $[a]$ pyrene. Int Biodeterior Biodegradation 45(1-2):57-88

Kebria DY, Khodadadi A, Ganjidoust H, Badkoubi A, Amoozegar MA (2009) Isolation and characterization of a novel native Bacillus strain capable of degrading diesel fuel. Int J Environ Sci Technol 6(3):435-442

Kelsey JW, Kottler BD, Alexander M (1997) Selective chemical extractants to predict bioavailability of soil-aged organic chemicals. Environ Sci Technol 31(1):214-217

Lee PH, Ong SK, Golchin J, Nelson GL (1999) Extraction method for analysis of PAHs in coal tar-contaminated soil. Pract Period Hazard Radioact Waste Manage 3(4):155-166

Loehr RC, Webster M (1997) Effect of treatment on contaminant availability, mobility, and toxicity. In: Linz DG, Nakles DV (eds) Environmentally acceptable endpoints in soil: risk-based approach to contaminated site management based on availability of chemicals in soil. American Academy of Environmental Engineers, Annapolis
Loick N, Hobbs PJ, Hale M, Jones DL (2009) Bioremediation of poly-aromatic hydrocarbon (PAH)-contaminated soil by composting. Crit Rev Environ Sci Technol 39(4):271-332

Lu XY, Li B, Zhang T, Fang H (2012) Enhanced anoxic bioremediation of PAHs-contaminated sediment. Bioresour Technol 104:51-58

Nakles DV, Harju JA (1998) Sequestration of contaminants in soilstate of the science. In: Proceedings of IGT international symposium: environmental biotechnologies and site remediation technologies, Orlando, Florida

Nam K, Alexander M (1998) Role of nanoporosity and hydrophobicity in sequestration and bioavailability: tests with model solids. Environ Sci Technol 32(1):71-74

Nnamchi CI, Obeta JAN, Ezeogu LI (2006) Isolation and characterization of some polycyclic aromatic hydrocarbon degrading bacteria from Nsukka soils in Nigeria. Int J Environ Sci Technol 3(2):181-190

Olajire Abbas A, Brack W (2005) Polycyclic aromatic hydrocarbons in Niger Delta soil: sources and profiles. Int $\mathrm{J}$ Environ Sci Technol 2(4):343-352

Pinelli D, Fava F, Nocentini M, Pasquali G (1997) Bioremediation of a polycyclic aromatic hydrocarbon-contaminated soil by using different aerobic batch bioreactor systems. J Soil Contam 6:243-256

Schwarzenbach RP, Gschwend PM, Imboden DM (2002) Environmental organic chemistry, 2nd edn. Wiley-Interscience, New York

Silva S, Dos Santos EC, De Menezes CR, De Faria AF, Franciscon E, Grossman M, Durrant LR (2009) Bioremediation of a polyaromatic hydrocarbon contaminated soil by native soil microbiota and bioaugmentation with isolated microbial consortia. Bioresour Technol 100(20):4669-4675

Sutherland JB, Rafii F, Khan AA, Cerniglia CE (1995) Mechanisms of polycyclic aromatic hydrocarbon degradation. In: Young LY, Cerniglia CE (eds) Microbial transformation and degradation of toxic organic chemicals. Wiley, New York

Ward OP, Singh A, Van Hamme J (2003) Accelerated biodegradation of petroleum hydrocarbon waste. J Ind Microbiol Biotechnol 30(5):260-270

Wen B, Zhang JJ, Zhang SZ, Shan XQ, Khan SU, Xing BS (2007) Phenanthrene sorption to soil humic acid and different humin fractions. Environ Sci Technol 41(9):3165-3171

Zhang WX (1995) Effect of sorption on bioavailability of hydrophobic organic contaminants: experimental and model studies. $\mathrm{Ph}$. D. Thesis, Johns Hopkins University, Maryland

Zhang SY, Wang QF, Xie SG (2012) Molecular characterization of phenanthrene-degrading methanogenic communities in leachatecontaminated aquifer sediment. Int $\mathrm{J}$ Environ Sci Technol 9(4):705-712 